\title{
Family-School-Professionals Partnerships: An Action Research Program to Enhance the Social, Emotional, and Academic Resilience of Children at Risk
}

\author{
Elias Kourkoutas ${ }^{1}$, Theodoros G. Eleftherakis ${ }^{1}$, Elena Vitalaki ${ }^{2}$ \& Angie Hart ${ }^{3}$ \\ ${ }^{1}$ Department of Primary Education, University of Crete, Rethymno, Greece \\ ${ }^{2}$ Department of Preschool Education, University of Crete, Rethymno, Greece \\ ${ }^{3}$ Faculty of Health and Social Science, University of Brighton, Brighton, UK \\ Correspondence: Elias Kourkoutas, Department of Primary Education, University of Crete, Rethymno, Greece. \\ Tel: 30-283-105-7202. E-mail: hkourk@edc.uoc.gr
}

Received: April 19, 2014

Accepted: June 29, 2015

Online Published: August 11, 2015

doi:10.5539/jel.v4n3p112

URL: http://dx.doi.org/10.5539/jel.v4n3p112

\begin{abstract}
This paper presents an action research program (note 1) which was designed to support parents and primary school teachers, with the mediation of school professionals in order to enable them facilitate the school inclusion of at risk students or those with special educational needs. The aims, the organization process, and the implementation of the program, as well as its theoretical and practical aspects/components, are presented. Resilience and inclusive education are the key theoretical frameworks informing this paper. These both advocate parent-teacher-professional partnerships to promote a "holding school environment" and support children with difficulties to avoid exclusion. An action research methodology was chosen in order to set up this program with the aim of enabling teachers and parents to be more "resilient" and "inclusive" towards children with special difficulties. The evaluation of the program showed that teachers and parents viewed this model of intervention very positively and gained significant knowledge of practices related to their respective role.
\end{abstract}

Keywords: family-school-professionals, children at risk/with special difficulties, resilient model, inclusive education, partnership model

\section{Introduction}

Given that family and school environments are considered to have an enormous impact on children's lives, many researchers in school psychology and in education have been seeking empirical evidence regarding the efficacy of parental involvement, and partnerships between teachers, parents and professionals, to strengthen and foster the academic and emotional resilience of at-risk students (Albright, Weissberg, \& Dusenbury, 2011; Powel, Son, File, \& San-Juan, 2010). In fact, traditional clinical models have been strongly criticized as operating an exclusively medicalizing approach, drawing on a deficit-centered conceptualization of childhood disorders (Harwood \& Allan, 2014). Such models fail to explore and promote individual competence (e.g. social, emotional skill development) and contextual (family or school) resilience (Aumann \& Hart, 2009; Goldstein \& Brooks, 2007; Kourkoutas, 2012).

Teachers and parents definitely require specialized support as they strongly emphasize the rising complexity of pupils' social, emotional and behavioural difficulties and the higher demands placed upon them in terms of effective dealing with a wide range of issues (Antoniou, Plychroni, \& Kotroni, 2009; Kauffman \& Landrum, 2013).

The attention of research and practice has, recently, been placed on how to support teachers and parents addressing the social, emotional, and learning challenges of pupils with difficulties in a way that differs from classical clinical practice and promotes inclusion (Baker, Grant, \& Morlock, 2008; Barbarasch \& Elias, 2009; Kourkoutas \& Raul Xavier, 2010; Lines, Miller, \& Arthur-Stanley, 2011). In fact, it has been widely assumed that models which aim at establishing meaningful and reliable partnerships between the families of at-risk children and professionals who take an inclusive (non-medicalizing) approach can make a valuable contribution to enabling these students to 
better develop their potential and skills and avoid exclusion (Eberly Center, 2013; Dodge, 2008; Doll, Jones, Osborn, Dooley, \& Turner, 2011; Lines et al., 2011; Kourkoutas \& Giovazolias, 2015).

However, only a limited number of schools in European countries adopt these kinds of systemic partnership models in practice on a regular basis (Cooper \& Jacobs, 2011). In addition, few teachers seem available to be fully committed to intra or extra-curriculum practices that address the needs and difficulties of "problematic" students and their parents in an inclusive way (Christenson, 2004; Richman, Bowen, \& Wooley, 2004). Even fewer are adequately trained to go beyond the narrow context of their traditional role and work with parents from an innovative inclusive perspective in order to address the needs of their students with difficulties (Cooper \& Jacobs, 2011). Such conclusions are more valid for the Greek educational context, which lacks the culture and infrastructure to provide teachers and parents the conditions for a positive and reliable partnership (Zoniou-Sideri, 2006). In addition, the dearth of professional interdisciplinary teams that work in a systemic and partnership way providing guidance to parents and teachers for innovative ways of dealing with "challenging cases" of children is obvious (Kourkoutas, 2012).

Consequently, teachers, in the Greek educational context, feel exposed to high levels of stress when they have to deal with students who display problematic and disruptive behaviors or developmental disorders (Kourkoutas \& Giovazolias, 2015). They usually feel inadequate and unsupported in dealing with these challenges, and as a result they may experience negative emotions such as stress, confusion, depressive feelings, or even anger and rage (Kourkoutas \& Giovazolias, 2015). Teachers are, in addition, forced to cope with an increasing number of demanding or unsupportive parents who often lack the skills to support a child with difficulties, an international finding that is also valid for the Greek context (Fleming, Mackrain, \& LeBuffe, 2013; Kourkoutas \& Giovazolias, 2015).

\subsection{Family, School, and Professional Partnership to Promote Resilience of At-Risk Students: Risks and Benefits}

Teachers may sometimes be defensive when they are invited to cooperate on an on-going basis with parents or consulting professionals in a more systematic way (Christenson, 2004; Cooper \& Jacobs, 2011; Kourkoutas \& Giovazolias, 2015). They may be reluctant to talk about the problems they face in their classroom, believing they would be exposed to criticism or appear insufficiently trained to respond to the social-educational challenges of their difficult students.

The reluctance of some teachers to develop stable and collaborative relationships with parents might also be related to the fact that teachers may appear critical of parents of children with problems, since they may attribute all the children's difficulties to a dysfunctional or deficient parenting. In the Greek context, a recent study has shown that teachers do not trust parents' capacity regarding the education of their children, and they feel they will be exposed to criticism if they allow parents to get involved in educational issues (Kourkoutas, Georgiadi, \& Hadzaki, 2011). Other studies, at international level, have shown that the teachers' hostility and defensive attitudes regarding open and constant cooperation with parents are associated with stereotyped views of the child's upbringing, fear of being professionally disdained, lack of confidence in their pedagogical value and capacities, a lack of communicational and cooperative skills, a lack of positive experiences of structured activities and group work or of cooperation with other professionals and in organized groups, etc. (De Carvalho, 2001; Kourkoutas, 2012; Lines et al., 2011).

In some cases, regular communication and the partnership of teachers' working with parents appears to be more routine, although the issue of how best to support parents of children with complex needs to come into school is commonly flagged as a challenge. It has been found that parents of children with problems may avoid cooperating with the school because in the past they had experienced rejection and criticism by teachers and, in general, had had conflictual or unfruitful meetings with them (Kourkoutas \& Giovazolias, 2015). This may lead to the parents' forming misjudgments and defensive attitudes towards teachers (Kourkoutas \& Giovazolias, 2015). Yet despite the difficulties of engendering meaningful and productive cooperation, family-school relationships have garnered significant benefits for students, parents and teachers on many levels and for many aspects of family and school life, and can lead to very positive outcomes (Dearing \& Tang, 2010; Minke, 2000).

As for the students, many studies, at international level, show that constructive family involvement can lead them towards developing a more positive manner of engagement with school, improving their learning performance and building stronger relations with parents and teachers (Caspe et al., 2007; Esler, Godber, \& Christenson, 2002; Hawes \& Plourde, 2005; Henderson \& Mapp, 2002).

\subsection{The Theoretical Background of the Action Research Intervention Model}


The key theoretical elements that inform our understanding of childhood difficulties are resilience theory, and inclusive education frameworks that focus on relational processes, reducing risk factors (e.g., inappropriate teacher practice) and strengthening children's, parents' and teachers' social, emotional and learning capacities (Kourkoutas, 2012). Indeed, supportive and positive family-child and child-teacher relationships, consistent monitoring and supportive guidance from parents and teachers, as well as successful inclusion in school are among the most protective and promoting factors that research on resilience has identified (Mash \& Wolfe, 2013; Richman et al., 2004; Rohner, 2010). Many at-risk and disruptive or socially and academically "deficient" students are struggling with intense negative emotions resulting from troubled relationships and unresolved problems or academic exclusion in the context of both school and family. For this reason, extra emphasis is placed on "restoring" family and classroom dynamics, and on resolving problematic or conflicting relationships between at-risk children and their parents, teachers and peers (Kourkoutas, 2012). Creating a positive and embracing classroom and "relational" environment in which vulnerable children can boost their self-competence and stabilize a positive sense of self and academic resilience (by means of various techniques) can be very helpful for their development (Cohen, 2013; Doll, 2013; Heller, 2000).

Within the resilient counseling framework, teachers and parents are helped to gain a deeper insight into the child's internal world and better understand his/her inappropriate behavior and learning difficulties in order to help $\mathrm{him} /$ her act in pro-social ways (Kourkoutas, 2012). They are therefore more likely to abandon their ineffective practices and develop a more appropriate attitude towards the child (Kourkoutas \& Giovazolias, 2015).

The existing literature already highlights the components of a successful intervention within schools for at-risk children. The intervention should be multileveled and holistic, including the components of classroom techniques and peer interventions; counseling work with parents and teachers; and direct work with the child by means of various techniques (such as verbal guidance or talking therapies, e.g., processing of negative emotions, social skills training micro-programs, creative group activities, art therapy or art-based practices, actions that strengthen peer relationships, problem or conflict-solving intervention, social-emotional learning curricula, and so on) (Hart \& Heaver, 2013; Christenson, 2004; Kauffman \& Landrum, 2013; Kourkoutas, 2012). A supportive educational and relational environment can foster a resilient and inclusive school climate as well as mindful and creative thinking and action on the part of students, parents, and teachers (Cohen, 2013; Doll, 2013). Overall, research suggests that building strong relationships between educators and families of children with special difficulties, with the support of adequately trained professionals, can contribute to the development, both in teachers and parents, of competence in successfully dealing with the challenges of the social and school inclusion of those children (Adelman \& Taylor, 2010; Christenson, 2004; Kourkoutas, 2012).

In the Greek educational system, schools have a long tradition of adopting a rather authoritarian stance in working with families, as well as a stereotypically defensive attitude towards parental involvement and the school inclusion of disabled or children who are often termed "problematic" students (Zoniou-Sideri et al., 2006). At the same time, it has been noted that the Greek teaching cadre in general appears quite defensive about the involvement of parents in the school life. This has often led to critical or conflictual situations with parents of "difficult" or at risk students and therefore to more problematic situations for the most disruptive or vulnerable students.

\section{Specific Aims of the Action-Research Intervention Project}

The overall aim of the program was to support and help parents and teachers resolve the problems they are facing with at risk students/students with difficulties and develop strategies both in the family and school context that have a positive effect on those children's social and academic inclusion through the mediation of partnership model and the guidance of school professionals working in a resilient systemic perspective (see also Kassis, Graaf, \& Kourkoutas, 2015; Kourkoutas, 2012; Kourkoutas \& Giovazolias, 2015).

The specific objectives of the program were: (a) to help teachers and parents gain a more thorough insight into children's at risk psychology and difficulties, and (b) to help them adopt a more positive attitude towards them and find ways to promote their hindered strengths and potential. The program adopted an interventive-preventive solution oriented approach by which families and educators are helped to create conditions that facilitate the "problematic" students' learning engagement, and psychosocial development (Christenson, 2004; Kourkoutas \& Giovazolias, 2015). Results presented in this paper are the outcome of 5 consecutive programs, run every year, with the same team, between 2008 and 2011.

\section{Methodology}

\subsection{Participants}


The intervention program was carried out in the first, second and third grade classrooms of 4 urban public primary schools ( 5 classes in total) in the town of Rethymno (Crete), in a variety of time periods, as separate intervention-research projects (4 groups in total), between early 2008 and late 2011 . Ninety-four students (6-8 years of age) were in the particular classes at the period of the program implementation. Many of them (20-25) presented a number of difficulties varying in form, duration, intensity or severity, and source. The research-intervention team consisted of two school psychologists and a school counselor who were assigned the role of monitoring the group dynamics and facilitating communication among the members. A social scientist was charged with taking notes on the topics discussed and the communication dynamics. A pilot research was conducted in a series of local schools in order to identify the students with difficulties and the kind of problems teachers and parents were facing with those students.

\subsection{Rationale and Implementation of the Program}

The intervention project was realized in real school contexts. In this sense, the "action research model" was adopted as a methodological framework (Willig, 2008). One of the core principles of action research programs is to bring about change at both an individual and an organizational level by identifying and solving human problems in their natural environment (Campbell, McNamara, \& Gilroy, 2004). To achieve such a goal, parents and educators were encouraged to bring their knowledge of the child and talk about their feelings or think about the strengths and the factors that might have hindered or delayed their children's psychosocial and academic adjustment. This kind of reflective dialogic process allows the participants to explore the phenomena under question in an intense and deep manner and to produce new forms of knowledge and suggestions for practice (Campbel et al., 2004; Kourkoutas \& Giovazolias, 2015). Throughout the project, every 20 days, on average, meetings were held, each lasting from 2.5 to 3.5 hours, in which all parents could freely participate and were encouraged to express themselves about the difficulties they were facing at home with their child or. Basic ethical principles governed the group dynamic and exchange, as in many cases the parents and the teachers of the children's cases were both present.

A total of 20 sessions were realized for each program, every year for a period of 4 years, with on average 15 participants (parents and teachers included) in each session. Each meeting was followed, the next day, by a meeting of the research-intervention group with an external academic researcher, in order to proceed to a comprehensive review of the topics that had been raised at the session with the teachers and parents, in order to identify issues for further elaboration and/or attempting to retrieve meaningful information from the material.

The meetings were tape-recorded, and the issues raised were analyzed and categorized into themes by two external social scientists with experience in content analysis and categorization. A high inter-rater reliability $(\mathrm{a}=$ 0.72 ) was achieved.

\subsection{Evaluation of the Program}

Questionnaire: The evaluation was conducted with the use of a 15-point questionnaire administered to parents, which built upon tools used in previous similar studies (Salinas, Epstein, Sanders, Davis, \& Davis, 1997). The questionnaire was enriched by items related to the specific cultural and educational conditions, as well as to the specific character of our program. Out of the 15 questions, 10 were closed and 2 open, and they tackled issues related to all aspects and subjects of our program procedure.

Interviews: A series of interviews were conducted with the classroom teachers and the school principals in order to allow them to freely express their opinions and ideas about the program process and outcomes. The school psychologists/counselors were also interviewed in order to record their experiences of the process and outcomes of the program, as well as their suggestions about the difficulties, weaknesses and strengths of the whole intervention.

The interviews were audio-recorded and transcribed. Tesch's (1990) systematic open coding process was applied during the data analysis phase, which allowed the segmentation of raw data into various themes and categories that were verified by independent coders during a consensus meeting. Credibility was established by transcribing the audio-recorded interviews verbatim, with prolonged engagement in the field, as well as the use of reflective and observational notes. The credibility of the data was enhanced by checking the correctness of the transcripts with most participants after the interviews had been transcribed.

\subsection{Issues Raised during the Group Meetings Process}

According to the thematic categorization of the data gathered, the following main issues, raised by the parents or the teachers, on the basis of specific children's problems, were dealt with in the group meetings: (a) the nature and the sources of specific students' learning difficulties and how to help them overcome such difficulties; (b) 
the nature, the function, and the sources/causes of specific students' disruptive, or aggressive behavior, and emotional difficulties and how to respond to each child separately; (c) how to assist students with developmental difficulties/disorders (Asperger, autism) being included in the classroom or how to improve their social skills; (d) how specific family dynamics might be harmful or troubling and how to resolve family conflicts or issues positively with "disruptive" children and avoid punitive or harsh methods of dealing or positively relating with the "problem" child; (e) how to avoid victimization and how to help victimized children overcome such a traumatic experience or how to help bullies reduce their intentional harmful behavior; $(\mathrm{g})$ the father's role in cases of problematic school and social pathways; (g) parents-teacher collaboration in order to apply a meaningful plan of intervention for many of the discussed cases of children. The discussion was focused on understanding the individual, family, and school dynamic of specific cases of children, as well as on discussing on how to respond at individual, parental, or teaching and school or classroom level. All participants (teachers and parents) were invited to voice their ideas, beliefs, or suggestions on how to help parents and teachers better respond to the challenges raised by the child's difficulties or special needs. In several occasions, children's cases were discussed and elaborated within the group, in repetitive meetings. A special emphasis was given by the intervention team to follow and evaluate children's academic and psychosocial progress in the family and school context.

\section{Results of the Program Evaluation}

Questionnaire: Regarding the overall value and the effectiveness of the counseling (focus group) meetings between teachers, parents and professionals, $71(100 \%)$ parents agreed that the meetings had been useful and successfully conducted, providing meaningful and comprehensive information to parents regarding many aspects of child, family, school function, and mutual interactions.

Almost all parents (90\%) found these meetings enlightening regarding their role and their attitude towards their child, and hence evaluated the experience of getting involved in this program very positively. Most of them reported that it had allowed them to transform for the better their position and feelings towards their child with difficulties. Even those who didn't experience significant difficulties with their child found that the program enabled them to get a deeper insight into the challenges their child experiences in his/her life, as well as their limits and strengths.

Almost all parents reported that the program allowed them to get a clearer picture of the difficulties and limits of the teaching process. They also became aware of the stress teachers experience and the efforts needed to respond to the challenges of teaching high-performance students while also including children with serious difficulties in the classroom.

Most of the parents (89\%) (including 93\% of those with "difficult" children) mentioned that they were very satisfied by the way the professional had dealt with a number of "burning" issues related to rearing practices and their child's school and social life. They mentioned they got adequate and enlightening information on issues related to: (a) children's behavior-socialization at school; (b) students' psychosocial development; (c) relationships and communication with other children; (d) social-emotional, behavioral, and learning problems; (e) cognitive skills; and (f) organization of homework.

Furthermore, many of them $(60 \%)$ were given the opportunity to change their views on and handling of their children's social-emotional and learning difficulties and $84 \%$ said they could now share their experiences with other parents.

More specifically, many reported that even if their problems had not been totally resolved, they felt they had truly been guided in new directions, changing perspectives and attitudes on many issues in the areas of parenting or communication with their children (29 parents), and mentioned feeling more capable of dealing with their children's developmental or social emotional challenges (24), finding solutions they would never have thought of (19), paying attention to and better understanding the inner dynamic of their own children's behavior (15), being more tolerant and flexible towards their children's academic or social and interpersonal difficulties (14), being less affected or more firm towards their children's behavioral challenges and problems (12), and better supporting their children in case of social exclusion or victimization (7).

All 71 parents $(100 \%)$ found the involvement of a school counselor and psychologist in the program crucial in helping them become more aware of the underlying psychological processes or emotional states and developmental challenges that their children experience. They also reported that they had become more aware of how their attitudes might affect their child's development. 
A high number (77.42\%) reported that they had had the opportunity to express their concerns and anxieties within the group and that this enabled them to better deal with the stress of rearing a child appropriately given the developmental changes and the everyday life challenges they were facing.

The vast majority (91\%) clearly indicated the need for counseling and psychological support and guidance on issues related to parenting in the child's school life, and all of them emphasized how important it was for them to continue the same program next year.

Overall, regarding the most significant things parents got from this program, the majority (89\%) believed that they were given the opportunity to have a better awareness of their child's school procedure and the problems their children might encounter at school, and be better guided in tackling them. They also mentioned that they had become aware that rearing children is not an "individual business" but "a social one", and that they have to enter into "partnership" and collaborate with other parents, and be guided by "good enough" professionals when needed.

\subsection{Summary}

In conclusion, according to the parents' answers, the majority did acquire substantial knowledge and insight regarding most aspects of their children's psychosocial life at school. Moreover, parents were helped to better understand the psychology and the psychosocial difficulties or needs of other children, to communicate with other parents, and generally to understand the class dynamics and the teacher's role in it. Parents also felt that their involvement in such groups made them be more reflective and self-critical and less critical towards school and teachers.

\subsection{School Principals and Teacher Interviews}

The interviews with the school principals and the teachers were scheduled two weeks after the program was over and conducted by two independent psychologists. The school principals' and teachers' interviews for both sessions lasted between 40 to 45 minutes and were tape-recorded and codified by the two external researchers.

Regarding the issue of teachers' support and guidance by school psychologists, all school principals firmly highlighted the role of the social-emotional dimensions of schooling and educational praxis, as well as the challenge to associate the child's family experiences with his/her development or behavior and deal with parental demands or their distorted expectations:

... Teachers need emotional support in everyday life and specific knowledge about their problematic students' needs and behavior and how to deal with their parents. (SP1)

Parents often put extreme pressures on teachers; they expect teachers to resolve their problems. Sometimes, they are not even aware of their child's difficulties or refuse to acknowledge them (SP2).

Similarly, the teachers $(\mathrm{T})$ pointed out the significance of the experience gained by the implementation of the program and the assistance they received in order to broaden their knowledge on how to approach children and their parents:

I felt much more confident in my actions, especially regarding those students with difficulties and their parents (T1).

Finally, the issue is to be supported, to feel confident and secure in what you think or you need to do... (T3).

A School Principal stressed the significant impact of such programs in the teacher's professional development and broadening of his/her role:

... Through the discussion of children's cases, teachers became more sensitive and helpful to parents and students (SP3). ...the teacher is also helped to develop his teaching skills and to overcome stereotypes and weaknesses that keep teachers and parents at a distance. (T2)

Another one affirmed:

the program gave me the opportunity to communicate better with the class and many of the parents; it has broadened my mind as a school principal. (SP4)

Another teacher also stressed the significant help educators, principals and parents can receive from a school counselor or psychologist who acts as a mediator among teachers, students and parents and can help them understand each other:

... I was really helped to open a door of communication with the parents and understand how hurt a parent may feel when he is invited to school to be informed about his/her child's problems. (T3) 
We had the opportunity to work out most students' learning and psychological issues and think on what went wrong with our attitude or strategy. (T3)

...this program helped us go beyond the disorder and see and feel the child with his real problems; sometimes, your intuition is restrained by the anger and stress you may feel. (SP3)

...often, we miss the focus on child's strengths and potential, as we are overwhelmed by his difficulties or pressures and challenging behaviors. (T4)

...I'm sure many of the parents behave to their child differently now, as I think our teacher does (SP4)

All participants (teachers and principals) highlighted the fact that working with the professionals (school psychologist and counselor) "was really an excellent experience", in terms of feeling "comfortable", "trusting", "equal with" and "valued by them" that helped being more confident and develop a better attitude towards their students, especially those with difficulties (SP1, SP2, SP3, SP4, T1, T2, T4, T5). All of them stressed the fact that the professionals worked in a "democratic partnership" allowing them to "think and reflect on their own attitudes and experiences" (T1, T2) and actively "participate" and "contribute new ideas" (SP1, SP3, T2, T3, T4, T5) "by taking a step back from the critical situation", "bouncing up", being more "creative" with their students. This way those with special difficulties, "problematic behaviors had more changes to be in contact with teachers and their In contrast with classical clinical school counseling, where most of them are excluded from the process of All of them underscored that this was an excellent.

In conclusion, all participants (teachers and parents), as they had the opportunity, acknowledged the positive experience they had gained from their involvement in the program, especially in terms of understanding and better responding to children's difficulties and of effectively communicating between them at long term. They also found extremely useful the fact that they shared a common space with parents and professionals, overcoming the fears of critics, and producing new ideas as they became emotionally closer to the parents.

\subsection{Biases, Difficulties and Limitations of the Program}

It is clear that the aim of this project was not to experimentally test an already implemented or manual-based intervention program in terms of its efficacy in changing children's social and academic outcomes. Yet although this project was situated within a different methodological perspective, it is considered extremely important to produce valuable data on how families, teachers, and children are affected or influenced by such projects. In this sense, although, parents and teachers were very positive towards the whole project, there was no opportunity to assess the immediate or long-term effects of the intervention program and of parents and teachers on children's with difficulties psychosocial and academic development.

A post-intervention qualitative measure has been distributed two years later to the parents $(70 \%$ of parents have responded), with still positive comments on their children's development by most of them. Detailed analysis of these findings is not included in this paper.

The parents' social-education level was quite high, and it is not clear that parents from other social-cultural backgrounds would respond positively to a similar program. In addition, the specific backgrounds, experience and training of the school counselors had an obvious impact on the way this project was developed and implemented. School psychologists from another background or with a different theoretical orientation and training would not necessarily achieve similar outcomes.

\section{Conclusions}

According to the innovative theoretical approaches in educational psychology, resilience processes and positive relational contexts are key aspects of the "inclusive school". An inclusive school means a school that cares for and promotes the well-being of all students, and especially those facing various internal or external challenges and barriers (Fleming et al., 2013; Cohen, 2013). As research suggests, change in parents' and teachers' attitudes and in strategies used to deal with children's problems is a key aspect of a successful education, both in family and school context (Albright et al., 2011; Shure \& Aberson, 2013). Enabling teachers and parents to develop mindful skills and getting meaningful insights into children's problems by providing them with new tools of conceptualizing the children's difficulties was one of the main goal of this project. The difference between our program and the similar programs in other countries is that we have placed a particular emphasis on working with parents and teachers" emotions, stemming from their difficulties in educating the "troubling" or "troubled" and with complex needs children. Our effort was to create a space of learning and exchange of experiences that would allow teachers and parents to become more mindful and resilient, by abandoning their negative emotions and attitudes. When such groups are effectively animated and participants are encouraged to develop their 
critical and creative thinking this may lead to surprising results in terms of exploring and inventing new ways of dealing with the children's problems (Hart et al., 2007; Kourkoutas \& Giovazolias, 2015). In fact, research suggests that reflective practice and collaborative conversations support the kind of collaborative, critical thinking that leads to resiliency (see Mohr et al., 2003).

In addition, at emotional level providing teachers the opportunities to share their concerns, worries, and distressing emotions, without being criticized, and discussing strategies on a practical level and on the basis of the of each "difficult" child case analysis was one of the strongest assets of this program, according to the teachers' views. Similarly, parents found extremely useful the possibility to understand their child's problems from a different perspective and gain a more profound insight, which seemed to allow them being less distressed ("guilty" or "responsible"), or critical and rejecting.

Summarizing the results of the evaluation of our program, the following conclusions, which are also supported by the international research, can be drawn: the positive cooperation among parents, teachers and school psychologists seemed to be beneficial for the school and the family, especially for those teachers and parents who were facing additional challenges in, respectively, educating and rearing children with special difficulties or problems. Teachers were helped to regain self-confidence and reengage with the "problematic students" in a relationship free of distress, conflicts and negative emotions. According to their statements, this way, they have been able to find new roles and gain better theoretical knowledge and practical experience, on the basis of the case discussions within the group. Teachers believe that, within this program, have been offered the opportunity to develop the skills to understand and approach the family with a new look. They became able to understand how parents' attitudes are connected with their children's problematic or "deficient" behavior and performance at school. This seemed to be very helpful for them, as they avoided to develop negative strategies, which often was the case in the past. Many of them stated that even if they knew that some students come from difficult or dysfunctional family backgrounds, they would never be able, without support, to avoid reacting in emotionally inappropriate ways, especially towards those children with challenging behavior.

The type of group meetings and the chosen/opted practical and theoretical perspective seemed to enable both parents and teachers to gain insight into children's difficulties and social-emotional problems and "go beyond the symptoms to meet the real child". The parents, according, to their statements, had the opportunity to express their concerns (group receptor of negative emotions), to come into contact with other parents, to better understand other children's problems, to strengthen their relationships and build trust in the school.

Adopting a systemic, child-centered and partnership approach to creating a "space" of exchange and meaningful analysis of the children's difficulties and of the family and school dynamics seemed to be one of the most helpful elements of our programs. This has allowed teachers to become more receptive, according to their statements, and fostering classroom resilience and educational success is one of the most important conclusions as indeed is indicated by other research (see Cooper \& Jacobs, 2011; Doll, 2013). Furthermore, involving professionals, parents and academic researchers to create "spaces of shared learning" and "micro-communities of practice" in schools, focused on problem solving, might be beneficial for all (Hart et al., 2013).

On the other hand, as revealed by this program, working with parents and group specialists requires several modifications to the teacher's role and the philosophy of the school, as well as to the school counselors' and psychologists' role who have, in a way, to abandon the classical clinical approach and put emphasis on fostering relationship and partnership models (Hart et al., 2007). Such changes in the way of working with at-risk children may engender significant resistance on the part of the teaching staff and school professionals. For this reason, such programs should take care to deeply explore the needs of the teaching staff and realize any intervention with their assistance, providing them with considerable support (Cooper \& Jacobs, 2011; Kourkoutas, 2012; Kourkoutas \& Giovazolias, 2015). This will certainly be worth the effort; Schools which have developed successful programs of partnership between parents and teachers based on a social-emotional curriculum have significantly improved both their students' academic performances and their social, emotional and behavioral skills (Fleming et al., 2013; Webster Stratton \& Reid, 2010; Zins, Weissberg, Wang, \& Walberg, 2004).

In the Greek context there are many challenges ahead since very few intervention programs aiming at promoting resilience in schools and supporting children with complex needs and difficulties in an inclusive way are currently available. Moreover, some of the classical individual treatment models fail to produce significant positive outcomes, as they lack a systemic perspective and fail to ensure teachers' involvement and commitment (Kourkoutas, 2012). Having been expounded and experimentally tested in other cultural contexts, these programs generally fail to address the particular cultural features of the Greek educational community and family dynamics, and do not respond to the specific challenges the teaching staff experience. Enabling resilience in 
teachers, parents, and students is also an objective and challenge of the public health and the school system, all over the world (Shure \& Aberson, 2013).

\section{Implications for Practice}

Overall, given the current dearth in professional resources and the critical social and economic conditions faced by Greek society, it is imperative to develop flexible, comprehensive and more efficient intervention programs, so as to promote family-school cooperation and foster the resilience of teachers, parents, and children with difficulties. Our suggestion is that such programs should be child-centered, and not deficit-centered, and should be adapted to the specific needs and particular conditions of the school context, focusing on teachers' and students' strengths and carefully assessing and dealing with external or individual barriers and risks.

We must rise to this challenge since, early intervention and support for social, emotional and behavioral or academic difficulties is vital for child development, especially when there is a strong link between home and school experiences (Kirkbride, 2014). Research indicates that when strong working relationships between home and school are forged, there are positive outcomes for all (Beveridge, 2005; Sanders, 2007).

\section{References}

Adelman, H. S., \& Taylor, L. (2010). Mental health in schools: Engaging learners, prevention problems, and improving schools. Thousand Oaks, CA: Corwin Press.

Albright, M. I., Weissberg, R. P., \& Dusenbury, L. A. (2011). School-Family partnership strategies to enhance children's social, emotional, and academic growth. Newton, MA: National Center for Mental Health Promotion and Youth Violence Prevention, Education Development Center, Inc.

Antoniou, A. S., Polychroni, F., \& Kotroni, C. (2009). Working with students with special educational needs in Greece: Teachers' stressors and coping strategies. International Journal of Special Education, 24(1), 100-111. http://www.internationaljournalofspecialeducation.com/articles.cfm? $\mathrm{y}=2009 \& \mathrm{v}=24 \& \mathrm{n}=1$

Aumann, K., \& Hart, A. (2009). Helping children with complex needs bounce back: Resilient therapy for parents and professionals. London: Jessica Kingsley.

Baker, J. A., Grant, S., \& Morlock, L. (2008). The teacher-student relationship as a developmental context for children with internalizing or externalizing behaviour problems. School Psychology Quarterly, 23(1), 3-15. http://dx.doi.org/10.1037/1045-3830.23.1.3

Barbarasch, B., \& Elias, M. J. (2009). Fostering social competence in schools. In R. W. Christner, \& R. B. Mennuti (Eds.), School-based mental health a practitioner's guide to comparative practices (pp. 125-148). New York: Routledge.

Beveridge, S. (2005). Children, families and schools: Developing partnerships for Inclusive Education. London: Routledge. http://dx.doi.org/10.4324/9780203464700

Campbell, A., McNamara, O., \& Gilroy, P. (2004). Practitioner research and professional development in education. London: Paul Chapman Publishing.

Caspe, M., Lopez, M. E., \& Wolos, C. (2007). Family involvement makes a difference: Family involvement in elementary school children's education. Cambridge, MA: Harvard Family Research Project.

Christenson, S. L. (2004). The family-school partnership: An opportunity to promote the learning competence of all students. School Psychology Review, 33, 83-104. http://doi.org/10.1521/scpq.18.4.454.26995

Creswell, J. W. (2009). Research Design: Qualitative, Quantitative, and Mixed Methods Approaches (3rd ed.). Los Angeles: Sage Publications.

Cohen, J. (2013). Creating positive school climate: A foundation for resilience. In S. Goldstein, \& R. B. Brooks (Eds.), Handbook of Resilience in Chilrden (pp. 411-422). New York: Springer. http://dx.doi.org/10.1007/978-1-4614-3661-4_24

Cooper, P., \& Jacobs, B. (2011). From Inclusion to Engagement: Helping students engage with schooling through. Oxford: J. Wiley.

De Carvalho, M. (2001). Rethinking family-school relations: A critique of parental involvement in schooling. Mahwah, NJ: Erlbaum.

Dearing, E., \& Tang, S. (2010). The home learning environment and achievement during childhood. In S. L. Christenson, \& A. L. Reschly (Eds.), Handbook of school-family partnerships (pp. 131-157). New York, NY: Routledge. 
Dodge, B. (2008). A literature review of social skills training interventions for students with emotional/behavioural disorders. University of Wisconsin-Stout. Retrieved January 10, 2009 from http://www2.uwstout.edu/content/lib/thesis/2008/2008dodgeb.pdf

Doll, B. (2013). Enhancing Resilience in clasrooms. In S. Goldstein, \& R. B. Brooks (Eds.), Handbook of Resilience in Chilrden (pp. 399-410). New York: Springer. http://dx.doi.org/10.1007/978-1-4614-3661-4_23

Doll, B., Jones, K., Osborn, A., Dooley, K., \& Turner, A. (2011). The promise and the caution of resilience models for schools. Psychology in the Schools, 48(7), 652-659. http://dx.doi.org/10.1002/pits.20588

Eberly Center. (2013). Create an Inclusive Learning Environment. Teaching Excellence \& Educational $\begin{array}{lllll}\text { Innovation. } & \text { Retrieved } & \text { August } & \text { 5, 2013, }\end{array}$ http://www.cmu.edu/teaching/designteach/teach/learningenvironment.html

Esler, A. N., Godber, Y., \& Christenson, S. L. (2002). Best practices in supporting home-school collaboration. In A. Thomas, \& J. Grimes (Eds.), Best practices in school psychology IV (pp. 389-411). Bethesda, MD: National Association of School Psychologists.

Fleming, J. L., Mackrain, M., \& LeBuffe, P. A. (2013). Caring for the caregiver: Promoting the resilience of teachers. In S. Goldstein, \& R. B. Brooks (Eds.), Handbook of resilience in children (2nd ed., pp. 387-397). New York: Springer. http://dx.doi.org/10.1007/978-1-4614-3661-4_22

Goldstein, S., \& Brooks, R. (2007). Understanding and Managing Children's Classroom Behavior (2nd ed.). New York, NY: Wiley.

Harwood, V., \& Allan, J. (2014). Psychopathology at School. Theorizing mental disorders in education. London: Routledge.

Hart, A., \& Heaver, B. (2013). Evaluating resilience-based programs for schools using a systematic consultative review. Journal of Child and Youth Development, 1(1), 27-53. http://www.youngminds.org.uk/assets/0001/4864/hart_heaver_2013_schools_review_article.pdf

Hart, A., Davies, C., Aumann, K., Wenger, E., Aranda, K., Heaver, B., \& Wolff, D. (2013). 'Mobilising knowledge in community-university partnerships: What does a community of practice approach contribute?' Contemporary Social Science: Special Issue. 8(3), 278-291. http://dx.doi.org $10.1080 / 21582041.2013 .767470$

Hawes, C. A., \& Plourde, L. A. (2005). Parental involvement and its influence on the reading achievement of 6th grade students. Reading Improvement, 42, 47-57. http://journals825.home.mindspring.com/csj.html

Henderson, A. T., \& Mapp, K. L. (2002). A new wave of evidence: The impact of school, family, and community connections on student achievement. Austin, TX: National Center for Family \& Community Connections with Schools.

Heller, F. (2000). Creating a holding environment in an inner school. In N. Barwick (Ed.), Clinical counseling in schools (pp. 22-36). London: Routledge.

Kassis, W., Graaf, U., \& Kourkoutas, E. (2015). Communities of practice supporting teacher's resilience. Paper Presented at the International Resilience Conference "Pathways to Resilience III", University of Halifax, Nova Scotia, Canada.

Kauffman, J. M., \& Landrum, T. J. (2013). Characteristics of emotional and behavioral disorders of children and youth (International edition). Boston: Pearson/Merrill.

Kirkbride, R. (2014). "They were a little family": An exploratory study of parental involvement in nurture groups-from a practitioner and parent perspective. British Journal of Special Education, 41(1), 83-104. http://dx.doi.org/10.1111/1467-8578.12047

Kourkoutas, E. (2012). Behavioral disorders in children: Ecosystemic psychodynamic interventions within family and school context. New York, NY: Nova Science.

Kourkoutas, E., \& Raul Xavier, M. (2010). Counseling children at risk in a resilient contextual perspective: A paradigmatic shift of school psychologists' role in inclusive education. Procedia Social \& Behavioral Science, 5, 1210-1219. http://dx.doi.org/10.1016/j.sbspro.2010.07.263 
Kourkoutas, E., Georgiadi, M., \& Hadzaki, M. (2011). Teachers' perceptions of pupils' social dysfunctions: A combined qualitative and quantitative approach. Procedia Social and Behavioural Sciences, 15, 3870-3880. http://dx.doi.org/10.1016/j.sbspro.2011.04.387

Kourkoutas, E., \& Giovazolias, T. (2015). School-based work with teachers: An integrative comprehensive counseling model. The European Journal of Counselling Psychology, 3(2), 137-158, http://10.5964/ejcop.v3i2.58

Lines, C., Miller, G. E., \& Arthur-Stanley, A. (2011). The power of family-school partnering (FSP): A practical guide for school mental health professionals and educators. New York, NY: Routledge/Taylor \& Francis Group.

Mash, E., \& Wolfe, D. (2013). Abnormal child psychology (International edition). Pacific Grove, Ca: Brooks

Mohr, K. A., Wickstrom, C., Bernshausen, D. M., Mathis, J. B., \& Patterson, L. (2003). Sharing the challenge: Using threaded discussion groups to build teacher resiliency. International Electronic Journal for Leadership in Learning, 7(11), 1-13. http://ijll.journalhosting.ucalgary.ca

Powel, D. R., Son, S. H., File, N., \& San-Juan, R. R. (2010). Parent-school relationships and children's academic and social outcomes in public school pre-kindergarten. Journal of School Psychology, 48(4), 269-292. http://dx.doi.org/10.1016/j.jsp.2010.03.002

Richman, J. M., Bowen, G. L., \& Wooley, M. E. (2004). School failure: An eco-interactional developmental perspective. In M. W. Fraser (Ed.), Risk and resilience in childhood. An ecological perspective (pp. 133-160). Washington, DC: National Association of Social Worker Press.

Rohner, R. (2010). Perceived teacher acceptance, parental acceptance, and the adjustment, and behavior of school-going youths internationally. Cross-Cultural Research, 44(3), 211-222. http://dx.doi.org/10.1177/1069397110366849

Salinas, K. C., Epstein, J. L., \& Sanders, M. G. (1997). Starting points: An inventory of present practices of school-family community partnerships. In J. L. Epstein, L. Coates, K. C. Salinas, M. G. Sanders, \& B. S. Simon (Eds.), School, Family, and Community Partnerships: Your Handbook for Action (pp. 122-125). Thousand Oaks, CA: Corwin Press.

Sanders, T. (2007). Helping children thrive at school: The effectiveness of nurture groups. Educational Psychology in Practice, 23 (1), 45-61. http://dx.doi.org/10.1080/02667360601154600

Shure, M., \& Aberson, B. (2013). Enhancing the process of resilience through. In S. Goldstein, \& R. B. Brooks (Eds.), Handbook of Resilience in Chilrden (pp. 481-503). New York: Springer. http://dx.doi.org/10.1007/978-1-4614-3661-4_24

Tesch, R. (1990). Qualitative research. Analysis types and software tools. New York: Falmer.

Webster-Stratton, C., \& Reid, M. J. (2010). A school-family partnership. Addressing multiple risk factors to improve school readiness and prevent conduct problems in young children. In S. L. Christenson, \& A. L. Reschly (Eds.), Handbook of school-family partnerships (pp. 228-245). New York, NY: Routledge.

Willig, C. (2008). Introducing Qualitative Research in Psychology. Adventures in theory and method (3rd ed.). Berkshire: Open University Press.

Zins, J. E., Weissberg, R. P., Wang, M. C., \& Walberg, H. J. (Eds.). (2004). Building academic success on social and emotional learning: What does the research say? New York, NY: Teachers College Press.

Zoniou-Sideri, A., Deropoulou-Derou, E., Karagianni, P., \& Spandagou, I. (2006). Inclusive discourse in Greece: Strong voices, weak policies. International Journal of Inclusive Education, 10(2-3), 279-291. http://dx.doi.org/10.1080/13603110500256046

Note 1. This project has been partially financed by the Economic Social Research Council, UK.

\section{Copyrights}

Copyright for this article is retained by the author(s), with first publication rights granted to the journal.

This is an open-access article distributed under the terms and conditions of the Creative Commons Attribution license (http://creativecommons.org/licenses/by/3.0/). 